\title{
Decentralized decision support for intelligent manufacturing in Industry 4.0
}

\author{
Maria Marques $^{\mathrm{a},{ }^{*}}$, Carlos Agostinho ${ }^{\mathrm{b}}$, Gregory Zacharewicz ${ }^{\mathrm{c}}$ and Ricardo Jardim-Gonçalves ${ }^{\mathrm{d}}$ \\ a,b Center of Technology and Systems, CTS UNINOVA2829-516 Caparica, Portugal \\ ${ }^{\mathrm{c}}$ University Bordeaux, CNRS UMR 5218, IMS, F 33405 Talence Cedex, France \\ ${ }^{d}$ DEE/FCT Universidade Nova de Lisboa 2829-516 Caparica, Portugal
}

\begin{abstract}
Industry 4.0" is recognized as the future of industrial production in which concepts as Smart Factory and Decentralized Decision Making are fundamental. This paper proposes a novel strategy to support decentralized decision, whilst identifying opportunities and challenges of Industry 4.0 contextualizing the potential that represents industrial digitalization and how technological advances can contribute for a new perspective on manufacturing production. It is analysed a set of barriers to the full implementation of Industry 4.0 vision, identifying areas in which decision support is vital. Then, for each of the identified areas, the authors propose a strategy, characterizing it together with the level of complexity that is involved in the different processes. The strategies proposed are derived from the needs of two of Industry 4.0 main characteristics: horizontal integration and vertical integration. For each case, decision approaches are proposed concerning the type of decision required (strategic, tactical, operational and real-time). Validation results are provided together with a discussion on the main challenges that might be an obstacle for a successful decision strategy.
\end{abstract}

Keywords: Industry 4.0, Decentralized Decision Support, Manufacturing, Industrial Digitalization

\section{Introduction}

Recently, the term "Industry 4.0" has invaded all conversations about the future of industrial production. What started as a national initiative in Germany, rapidly evolved to a much more extended concept that is being used to identify what it is seen as the next industrial revolution [1]. In an initiative lauched in April 2016, the European Commission recognizes the importance of promoting measures to support the development of a digitized european industry aiming to to ensure that Europe is ready for the emerging challenges of digital products and services. Moreover, similar approaches are being followed outside EU (e.g. China has launched "Made in China 2025", United States created the "Smart Manufacturing Leadership Coalition" (SMLC) initiative, etc.).

The main goal of all these initiatives is to achieve the intelligent factory characterized by adaptability, resource efficiency, and ergonomics, as well as the integration of customers and business partners in business and value processes [2]. To achieve this challenging objective companies must cope with the increasingly stricter requirements in terms of flexibility, while maintaining their production capacity [3].

Currently, industrial companies are pushed to take 'glocal' actions, i.e. thinking globally but acting and staying economically compatible with the local context [4]. The same can happen inside the factory, where enterprise level strategy needs to be accompanied by local action at the resources and devices level. As an example, integrated systems for machining (e.g. CNC machines) are used worldwide, and organizational strategies need to be flexible to accommodate highly variable domains of application and consumer policy restrictions, configuring and allocating resources in-house depending of the product variant.

Manufacturing is typically associated to the transformation of raw material and assemblage of

\footnotetext{
* Corresponding author. E-mail: mcm@uninova.pt. Tlf: +351212948 529. Fax: +351212957786
} 
components into final products that fit the needs of many and can be sold worldwide. As a consequence, research and development (R\&D) in this domain has targeted the acceleration and mass-replication of more or less static production processes, construction of production machinery and the development of software to control such systems. However, the last decade has demonstrated clear signs that industry cannot proceed with 'business as usual' practices. As identified by the European Commission's Future Internet Enterprise Systems cluster (FInES) roadmap in 2012, a change of paradigm is required to maintain and improve the current standard of life [5].

Mass replication, although still an important part of production, tends to lose space for customised products tailored to fit consumer needs and demands [4]. Also, as production stages and technologies have become more mobile, a single final manufactured good is nowadays often processed in different companies and countries, crossing several information systems (IS) with sequential tasks in the value chain. Therefore, the survival of enterprises in the near and long term future will depend on their ability to see their own role within the physical and social environment and to become flexible to changes in paradigm that can give them a competitive advantage.

The advances in digital automation can contribute significantly to help unleashing their potential to respond to these challenges [6]. Indeed, the explosion in the Internet of Things (IoT), and the shift towards a new industrial paradigm based on cyber physical systems (CPS) are paving the way.

In a Smart Factory (SF), everything is connected [7]. Production machines, humans, products, transport options and IT tools communicate with each other and are organized with the objective of improving overall production, not only within the physical boundaries of the company but also beyond them. One of its key characteristics is the ability to decentralize control and decision as it facilitates modifications in the production process contributing to meet the increasing demand for mass customization.

This paper starts by identifying opportunities, challenges and main charateristics of Industry 4.0 in section 2 followed by an analysis of the main barriers to its implementation in section 3 . Then, in section 4 the need for Decentralized Decision Making is discussed and the main areas in which it is needed are identified. Strategies for supporting decision in these areas are presented together with main contraints. In the end initial validation results are presented following discussion on how these should be takled.

\section{Industry 4.0: Opportunities, challenges and main characteristics}

When discussing how companies should be addressing the opportunities provided by Industry 4.0 it becomes obvious that some of them are still waiting for more clear advantages in joining the new paradigm. On the other hand, the examples of companies that are modernizing themselves keeps growing. This difference in attitude can be critical for the success, in the middle to long term, of companies that are not accompanying the trend.

Despite their position towards Industry 4.0 companies identify a set of opportunities regarding its adoption ([1]), namely:

- Increased competiveness: digitalization of industry will increase their competitiveness as it will impact both local and global value chains

- Easier adaptation to market changes - from "push into the market" to "pull from the consumer": the immense potential of industry 4.0 will facilitate the integration of customers needs and preferences into the development of new products and adaptation of production processes

- Risk and fault reduction: data integration and data analysis contribute for improved monitoring and thus reduce down times and faults. Cyber security will also be reinforced reducing hackerism risks.

- Skilled workers and IT: investements on the education of workers as well as in appropriate infrastructure, although mandatory in most cases, are also seen as an opportunity for improving performance

- Use of currently growing technologies: smart sensors, 3D printing, etc., are seen as the key for accelerating the transformation for industry 4.0 by enabling rapid testing, prototyping and production adaptation.

It is possible to analyse the identified set of opportunities and to correlate them with some of the most promising technological developments that are considered the biggest contributors for making Industry 4.0 a reality. Concepts such as CPPS (Cyber-Physical Production Systems), and IIoT (Industrial Internet of Things) have emerged and represent challenges that need to be tackled to answer 
the requirements of a continuously changing environment.

With roots on CPS, CPPS are systems of collaborating and autonomous across all levels of production, from processes through machines up to production and logistics networks [8]. They are capable of acessing, providing and using production data from real world at real-time. Aspects such as sovereignty, collaboration, optimization and responsiveness need to be especially addressed by CPPS. In addition to that, simulation, sensor networks, big data and security issues represent an important part to deal with challenge of CPPS implementation.

The recent advances on smart sensors, wireless networks and embedded systems, together with the consistent decrease of technology costs have contributed for the rapid development of industrially oriented IoT. Thus, IIoT appears as the main driver for the implementation of Industry 4.0 and is directly related with the successful development of CPPS. Making use of technologies such as data acquisition and data integration, capabilities to capture and fuse information from various sensors/objects and cloudbased data centers, IIoT facilitates the adjustement of production parameters, opening new perspectives in easy reconfiguration of production lines, effective detection of failures, autonomous maintenance triggering and prompt reaction to unexpected changes in production. Although the possibilities for their application are immense there are still some technological issues that need to be addressed to ensure the full implementation of IIoT (e.g. semantic integration and analysis for which additional developments on standards and protocols are needed).

CPPS together with IIoT enable the creation of a smart network of machines, ICT systems, smart products and people across the entire value chain and the full product life-cycle. Interfacing with other infrastructures is also a reality enabling access to information coming from other smart platforms (e.g. smart logistics).

One key challenge is the introduction of the consumer persective in the production process with the trend on customization growing every day. Maufacturing, especially in western countries, is no longer based on mass production but on mass customization in a "lot size 1" approach. Thus, links with social media networks are fundamental to access consumer expectations and desires.

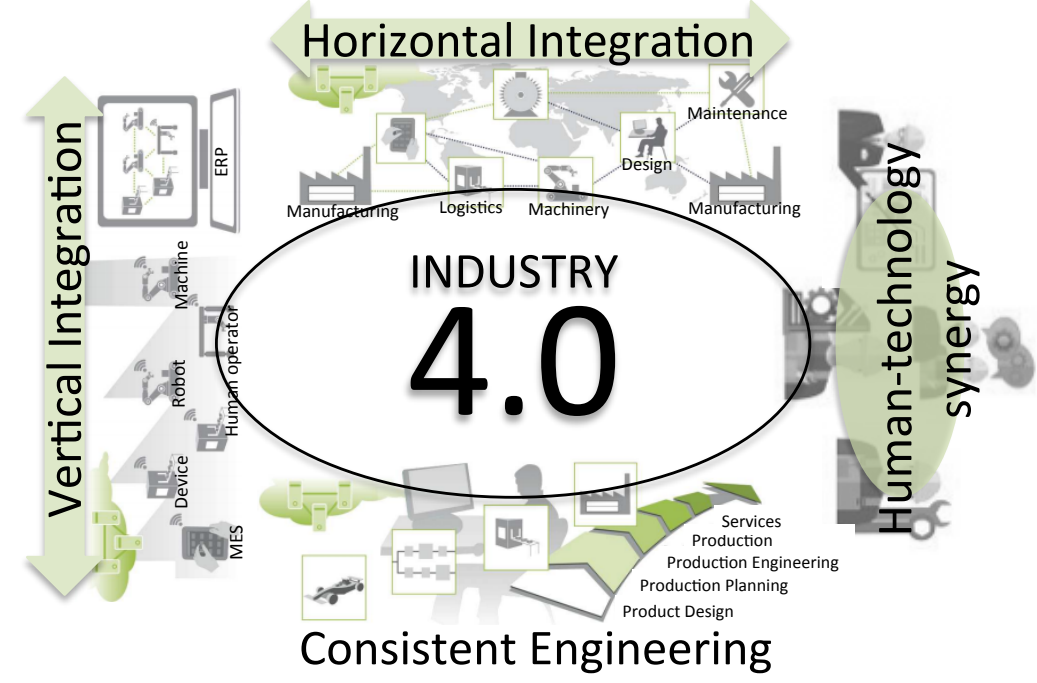

Fig. 1. Main characteristics of Industry 4.0 (adapted from [9])

To answer to the identified challenges and needs Industry 4.0 is composed by four main approaches that demonstrate its enormous potential for change (see Fig. 1):

- Vertical integration: responsible by the vision about high flexibility on production towards full customization ("lot size 1") by fully integration of the internal value chain of the company.
- Horizontal integration: enables the inclusion of worldwide value network, and allows to work both on the processes as well on the systems till delivery of product to the customer.

- Consistent engineering: complete systems engineering, through production digitalization, from product design to product distribution, disposal and aftersales services. 
- Human-technology synergy: promoting new skills and competences from the workforce, adapting working conditions (more attractive and productive) and safeguarding jobs.

\section{Barriers for industry digitalization}

All the aforementioned aspects can only be succeeded if supported by the developments on the areas previously mentioned. But, on the other hand, technological developments must be combined with social sciences and humanities in order to achieve human-technology synergy.

In fact, companies recognise that having the right people in place is critical for leveraging technological gain, and to accomplish the goals of smart manufacturing. The current perception about the socalled "skills gap" is that it will continuing growing as the percentage of new jobs needing highly skilled workers keeps increasing [7].

In addition to this, currently there is still a notion of manufacturing jobs as being less important in society, with lower incomes and poorly recognized. Many companies are facing huge difficulties in attracting talented resources to work with them as they are still very influenced by these views and companies need to work on their message to attract talents for industry [10].

Despite advanced digitization, horizontal integration, with suppliers, customers and other value chain partners, is progressing a slower than the vertical one [11]. Although the potential of greater horizontal integration is broadly recognised (e.g. offers the prospect of coordination of orders, materials flow and production data, with all companies along the value chain being able to add their own value-adding steps) there are still barriers that need to me removed to achieve it. These barriers are not only technological ones but also related with confidence and trust.

The World Economic Forum published the results of a 2014 [12] survey on Industrial Internet in which a set of barriers were identified by companies (see Fig. 2). The results demonstrated that almost twothirds of the two major issues are related with security and interoperability. Other significant barriers cited include the lack of clearly defined return on investment (ROI), legacy equipment and technology immaturity.

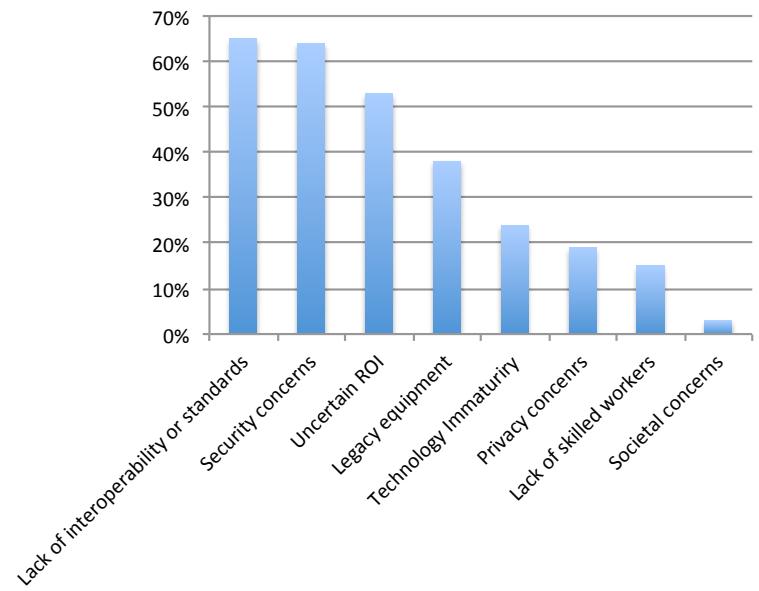

Fig. 2. Key barriers for industrial digitization

Thus, in the latest years, interoperability and standards has been one of the areas capturing majos attention from public and private institutions. In 2008, European Union launched Public-Private Partnership (PPP) for Factories of the Future (FoF). The FoF work program for 2018-2020 expects to mobilize more than $€ 50 \mathrm{bn}$ of public and private investment with great focus on the development of standards for : 5G, Cloud Computing, Internet of Things, Data technologies and Cybersecurity.

Interoperability is an essential problem of sharing information and exchanging services. It goes far beyond the simple technical problems of computer hardware and software, but encompasses the broad but precise identification of barriers not only concerning data and service but also process and business as well [13]. In fact, difficulties are observed when actors from various fields of expertise or with different types of resources, are forced to exchange information [14][15]. These difficulties arise at two levels:

- The difficulties to exchange data: observed when an actor does not have the proper tools to send or receive data. This is also observed when an actor is facing problems in accessing the content of the data files after receiving them.

- Difficulties in understanding the information exchanged: once the data exchanged, it must be ensured that the actors have a mutual understanding of the data. In fact, the diversity of actors and their areas of expertise, as well as differences in language and models complicate the uniqueness of meaning and understanding.

In what regards interoperability, traditional integration and interoperability services are often 
inflexible and difficult to adapt to meet dynamic requirements. Most development is either relying on international accepted standards for data exchange, e.g. $\mathrm{STEP}^{1}$, EDI/EDIFACT ${ }^{2}$, ebXML ${ }^{3}, \mathrm{UBL}^{4}$, or is implemented on a peer-to-peer basis [16] [16][18]. Architectures on integration and interoperability [19], modelling frameworks and tools, as well as methodological [20][21][22] are available but the real challenge resides in applying them to streamline data integration and interoperability while sustaining collaboration throughout market adaptation and innovation.

This sustainability convenes the needs of the present without compromising the ability of future changes, meeting new system requirements [22]. Integration and interoperability is acknowledged with many researchers working in related domains, such as the digital and sensing enterprise [24], smart networks [25], or digital business innovation and big data [26] In many cases, model driven and knowledge-based technology is being promoted [27], however they are rarely applied together and there is little concern on the company network sustainability, currently addressing interoperability only at the network design time. Jardim-Gonçalves et al. [28] define sustainable interoperability as the development of novel strategies, methods and tools to maintain and sustain the interoperability of enterprise systems in networked environments as they inevitably evolve with their environments. These developments are fundamental to establish and maintain interoperability within the company (intrainteroperability) and also in the value chain (extrainteroperability).

Additional work is also needed to develop widely accepted methods for privacy and security. One of the technologies that is positioning as being a strong possibility to deal with these issues is blockchain technology. It offers a way of recording transactions or any digital interaction in a way that is designed to be secure, transparent, highly resistant to outages,

\footnotetext{
1 ISO 10303-1:1994 Industrial automation systems and integration -- Product data representation and exchange -- Part 1: Overview and fundamental principles

2 ISO 9735: 1988 and ISO 9735-1:2002

3 ISO 15000-5:2014

4 ISO/IEC 19845:2015

5 Blockchain: a distributed database that maintains a continuously-growing list of records called blocks (each block contains a timestamp and a link to a previous), secured from tampering and revision.

(https://en.wikipedia.org/wiki/Blockchain_(database))
}

auditable, and efficient [38]. Its potential results from the following characteristics:

- Reliability and availability: in a network of participants, in case of node failure, the others will continue to operate, maintaining the information's availability and reliability.

- Transparency: transactions are visible to network participants, increasing auditability and trust.

- Immutability: changes are almost impossible to be made without being detected, increasing confidence in the information and reducing fraud opportunities.

- Irrevocability: transactions can be made irrevocable, increasing the accuracy of records and simplifying back-office processes.

- Digitalization: as almost any document or asset can be expressed in code, applications are endless.

Also, the development of mechanisms to support collaboration and information flow are also a key aspect for full horizontal integration. Nonetheless, to get there, companies have to get their vertical integration done first, starting at the heart of their production processes.

\section{Decentralized decision-making}

Spatial Integration can be achieved in a centralized or decentralized way. In a centralized decisionmaking (CDM) process, a single, decisional center (DC) is acquainted with all the system information. The central node is in charge of the system planning and owns the power to manage the operations performed by all the network nodes. The central node performs the decision- making in terms of optimizing the objectives of the entire network. In the decentralized decision-making (DDM) models each individual independent network entity makes its own decisions, trying to optimize its own objectives. More than one decision-maker is identified. Depending on the collaboration degree, the nodes will take into account (to a lesser or larger extent) the decisions of other nodes. In a DDM Collaborative mechanisms are needed to coordinate node's decisions and exchange the information [22][30]. In a DDM model each independent entity, or DC, has its own objective function, which is subject to its constraints. In addition, the decision variables for each entity are often influenced by other entities' decisions, and the flows between levels [31]. 
To manage interdependent relationships of DDM, it is necessary to define mechanisms that are capable of coordinating the decisions made by the different nodes, as well as the information they exchange. These coordination mechanisms can be found in preagreed business rules, and assessment and comparison of alternatives using performance measurement techniques [32][33][34][35]. Information is a key aspect for decision-making. The structure of the information systems (IS) is usually supported by legacy software such as Enterprise Resource Planning (ERP) or other centralized software. First challenge is to synchronize the information stored in the ERP and the information managed in the Manufacturing System and second is to achieve a real-time updating of the information regarding unforeseen events.

System Theory [36] states that "an organization reacts to conflict by using analytical processes or bargaining processes". In these way, the recommendation [37] is that the problem solving process of conflict resolution is to identify a solution that satisfies the shared criteria building a decisional structure in order to decentralize the decisionmaking, taking in account the coherence of the objectives between the levels of decision.

This approach enables the classification of decision considering the time-frame associated to the decision process (strategic, tactical, operational, realtime) and will provide the criteria to decentralize the decision and facilitate the reactivity facing unpredicted events.

In the context of multi-stage Supply Chains (SC), when focusing on a certain decision-making temporal level it is usual to connect the decisions of a specific SC part with the decisions of the rest of the SC parts, especially with those that are immediately upstream or downstream. This is similar when the focus is in the factory at different levels of the automation pyramid.

\subsection{Horizontal integration for decentralized decision support}

Value chains are distributed and dependent on complex information and material flows requiring new approaches to reduce the complexity of manufacturing management systems. They need ubiquitous tools supporting collaboration among value chain partners and providing advanced algorithms to achieve holistic global and local optimization of manufacturing assets and to respond faster and more efficiently to unforeseen changes.

The way how manufacturing and service industries manage their businesses is changing due to the emerging new competitive environments. According to [39] the enterprises' success in the new dynamic environments is associated to the improved competencies in terms of new business models, strategies, governance principles, processes and technological capabilities of manufacturing enterprises of 2020. Moreover, especially for SMEs, the participation in collaborative networks is also a key issue for any enterprise that is willing to achieve differentiated and competitive strengths. In the light of this, establishing collaborative relationships becomes an important issue to deal with customer needs, through sharing competencies and resources.

Collaborative Networks consist of a variety of heterogeneous autonomous entities, geographically distributed, in which participants collaborate to achieve a common goal and base their interactions through computer networks. SMEs are characterized by limited capabilities and resources; therefore, in order to overcome possible barriers that can appear when establishing collaboration, joint efforts must be performed to achieve the desired collaborative scenarios. When establishing collaboration, networked partners share information, resources and responsibilities to jointly plan, implement, and evaluate a program of activities to reach a common goal and therefore jointly generate value. Thus, establish collaborative relationships imply sharing risks, resources, responsibilities, losses, rewards and trust.

The last decades show a clear trend in business: away from big comprehensive trusts which can cover all stages of a value creation chain, and away from long-standing, well-established and stable supply chains [40]. Most of the companies are moving their focus on their core business competencies and enter into flexible alliances for co-value creation and production. This requires flexible business process integration strategy and interoperable models.

Recent works in interoperability have provided promising results and have been partly responsible for initial commercial products and service offerings and operational deployed applications as discussed in [41][42]. Collaborative systems need to be agile enough to address the changing needs in manufacturing processes. Agile and resilient enterprises have to cope with the complexity of information presented in many interconnected dimensions, and continuously adapt and re-organize 
themselves [43]. Representing the enterprise as a static system neglects issues raised by the dynamics of today's business [44].

To achieve this level of collaboration companies must be capable of interoperate. Enterprises today face many challenges related to the lack of interoperability as most of their Information and Communication Technology (ICT) solutions are often inflexible and difficult to adapt to meet the requirements of those changing enterprises [45].

Assuming that the problems regarding interoperability are solved and that all the network participants are able to communicate and understand each other, a new range of collaboration opportunities is open. Among these, the possibility to implement mechanism for decentralized decisionmaking. In this context we are basically looking for decision that are strategic (i.e. related to network's mission and objectives) and/or tactical (decisions that will contribute to the longevity, profitability, and continued improvement of all areas of operation).

As we are focusing on decisions that are made within a network of stakeholders procedures that enable decentralized decision making are sought. In these cases the decision making methods are not the central part of the problem. Instead, the most important aspects are related with the establishment of the decision process. For this [46] proposes a sixstep approach to facilitate the collaborative decision making:

1. Ensure leadership and commitment: despite the collaborative nature of the process, the existence of facilitator that owns the process is defended to ensure the success;

2. Frame the problem: specifying known policies, givens, and constraints; identifying problem areas and uncertainties; and defining assumptions and details that are follow-on parts of the decision

3. Develop evaluation models and formulate alternatives: achieving consensus about how success will be measured is fundamental. Alternatives must be developed based on the network vision, framing of the problem and understanding of the issues requiring consideration and alternatives that overlap or are not independent must be identified.

4. Collect meaningful, reliable data: all decision processes require colleting the right information (i.e. the one that is critical for the decision to be made) in an appropriate amount (excluding information that can contribute to turn the decision process messy). The use of decision analysis tools (e.g. Nominal Group Technique NTG [47]) can be helpful for identifying what information is meaningful to the process and how it should be collected.

5. Evaluate alternatives and make decision: Evaluate identified alternatives and select the one that best fits the criteria. Several decision making tools can be used in this step from a simple cost-benefit analysis to multi criteria decision methods (e.g. Analytical Hierarchy Process - AHP [48])

6. Develop an implementation plan: success of the process depends on how decisions are implemented. The definition of an implementation plan allows to consider barriers, performance interventions, and project management issues. To support the development action plans and decision tree diagrams can be used.

Collaborative decision making is a complex task especially in what regards the human factor that is involved. Thus, the criticality along the process resides in the steps which involve interaction among participants and to reach a consensus. This is the reason why Step 1: Ensure leadership and commitment is the most important. The selection of the facilitator can also be made following different strategies. When focusing on value chain networks the facilitator this selection can be made using two different strategies:

- Select an impartial and trustworthy entity, external to the network;

- Within the network, select a different facilitator depending on aim of decision process.

In the second case, a set of rules must be defined at network setup to make this selection clear and accepted by all involved stakeholders. Also, if new partners join the network the set of rules must be communicated and accepted.

\subsection{Virtualizing the automation pyramid for vertical integration and decision making}

Smart Factory (SF) is a Factory that context-aware assists people and machines in execution of their tasks [49]. Mark Weiser [50] has coined the term ubiquitous computing for this new world. His vision as regards smart environments involves a physical world, closely and invisibly interwoven with sensors, actuators, displays and computer elements, which are seamlessly embedded into daily life objects and connected with each other by a network. Mark 
Weiser's approach of smart environments is transferred to manufacturing issues [49]. After the development of digital and virtual factories, the next step is the fusion of physical and digital/virtual world [51] under a so-called SF. The SF concept enables the real-time collection, distribution and access of manufacturing relevant information anytime and anywhere. Systems working in background accomplish their tasks based on information coming from physical and virtual world. SF represents a realtime, context sensitive manufacturing environment that can handle turbulences in production using decentralized information and communication structures for an optimum management of production processes [49]. SF products, resources and processes are characterized by cyber-physical systems where materials are moved efficiently across the factory floor. This provides significant real-time quality, time, resource, and cost advantages in comparison with the traditional production systems. Sensing components such as actuators and sensors within the industrial set-up are expected to become "smart" as they are, increasingly, becoming self-sufficient with integrated computing abilities and low power consumption. SF will involve consolidation of existing solutions based on a holistic integration of field devices and technologies, including contextaware applications, federation platform, sensor fusion, status recognition, embedded systems, calmsystems (hardware), communication technologies (wireless), auto ID technologies, positioning technologies, and assistance of people and machines [49]. This integration is being driven by the need for seamless exchange of business intelligence to enhance the efficiency by the optimization of resource planning, scheduling, and controlling in real time [52].

Industrial automation platforms are experiencing a paradigm shift. New technologies and production strategies are enabling a synchronization of the digital and real world, providing real-time access to sensorial information, as well as giving technological infrastructures advanced networking and processing capabilities to actively cooperate and form a sort of 'nervous system' within the factory [53][54]. Enterprise resources (e.g. assets in the form of materials, devices, people, etc.) can be transformed or consumed to produce such benefit. Yet, the development of applications that exploit knowledge from such heterogeneous resources will require a clear understating of all relations and interdependencies. Factory resources virtualization exposes an abstraction layer that removes inherent complexity and softens the inner-company operations, creating the conditions to improve agility, responsiveness, and decentralized decisionmaking[55]. Either by applying simple resource virtualization or mashup, factory virtualization allows to abstract, model and simulate the full automation pyramid, uniquely identifying and virtually representing the real physical entities (e.g. specific sensor) or some aggregation of them (e.g. combined knowledge) [56].

These technologies, when correctly used are capable of providing a huge impact on the factories daily operations. Supported by smart components delivering global and physical awareness to the business systems, they will enhance overall context awareness and the opportunity for better decisions.

Complexity science theorizes simple causes for complex effects, with rules that determine how a set of agents behave and interact over time within their environment. It does not predict an outcome for every state, and uses feedback and learning algorithms to enable systems to adapt to its environment over time. In the domain of factory systems, the application of these rules to a large population leads to emergent behaviour that may emulate real-world phenomena. Fig. 3 can be used to better explain the concept of the Smart emergent complexity and an enterprise organization.

It is easy to observe that the automation pyramid can be directly associated to complexity theories and the 'Glocal' factory idea:

- The bottom-up perspective (emergence) enables to understand how simpler systems can be aggregated to provide more complex functions in the frame of the decomposition structure. The proposed architecture relies on this idea and seeks to collect information and act on systems as simple as possible, making use of the pyramid to take input data and knowledge directly from the lower level devices and components up-to the enterprise level where production planning can be reconfigured, products redesigned, etc. Depending on the level of decision required, the emergent flow might not reach the top of the pyramid, decentralizing control and increasing automation.

- The top-down perspective (decomposition) allows to define the global structure of the pyramid by introducing decentralization mechanisms and modularization that will be responsible for decreasing levels of complexity to a point where simulation, visualization and 
decision can be distributed and used to facilitate control and actuation on the real world.

The combined bottom-up and top-down perspectives, enables the resolution of problems, offering a structure of decomposition that discovers inputs from localized mechanisms (e.g. selfadaptation triggered by smart objects), instead of always starting the "responsive" process from the higher level of the automation pyramid. This will create a feedback loop into the manufacturing process that allows reconfiguring and reorganizing physical, human and computational resources in a better form to respond to new trends in masscustomization and re-shoring, as well as unforeseen problems in the daily operation.

This concept is also tightly connected with the vision of Sensing Enterprise that was created to reconcile traditional non-native "Internet-friendly" organisations with the tremendous possibilities offered by the cyber worlds [57].

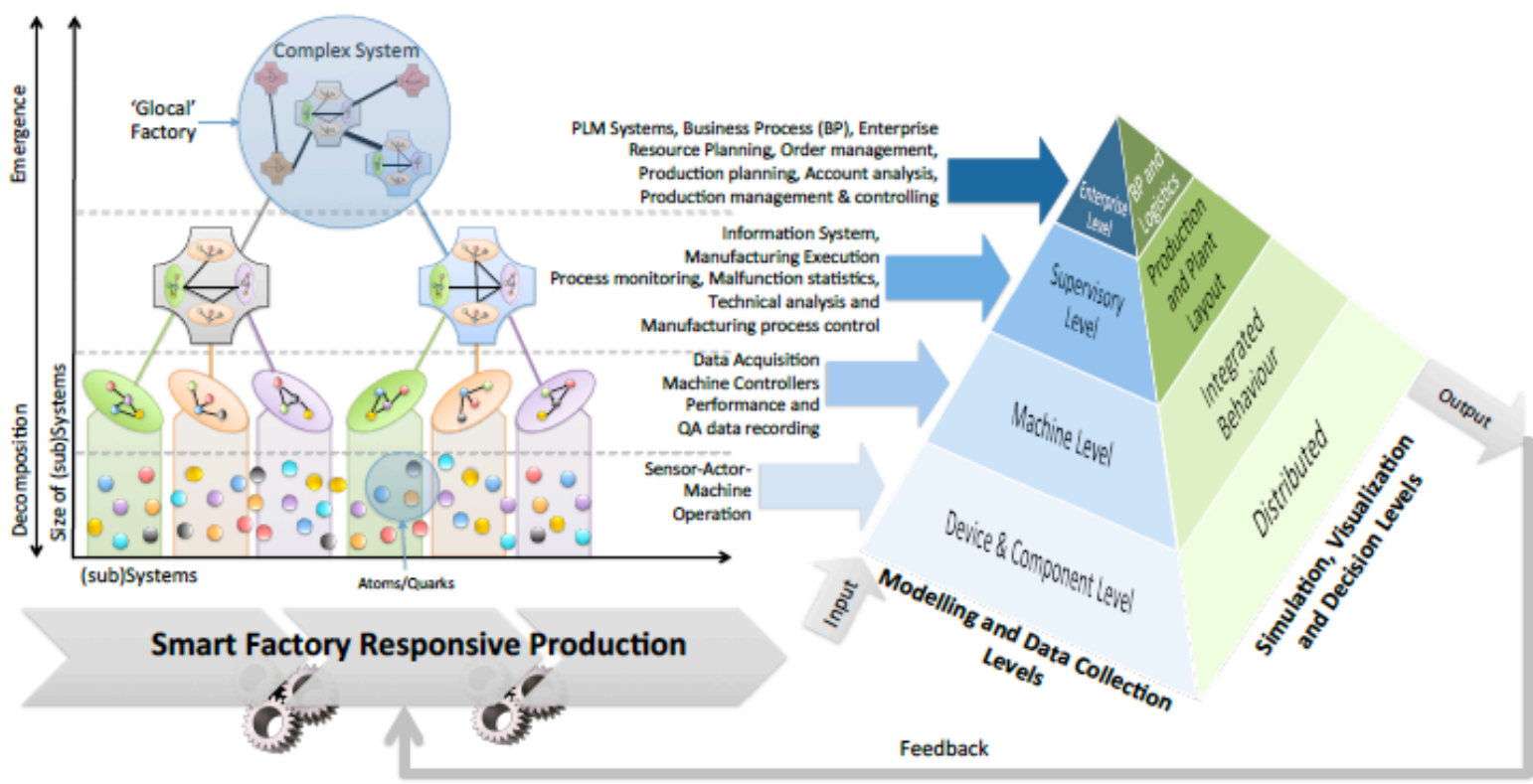

Fig. 3. Emergent behaviour and automation pyramid virtualisation: an analogy

This approach envisions the enterprise as a smart complex entity capable of sensing and reacting to stimuli, by integrating decentralised intelligence, context awareness, dynamic configurability and sensorial technology into its decision-making process. The enterprise uses visualization and simulation techniques to anticipating future behaviour and taking decisions on multi-dimensional information captured through physical and virtual objects. Simulation is running potential scenarios based on historical results projected in the future before final implementation. Within these processes, and when focusing on the higher levels of the automation pyramid (i.e. enterprise and supervisory levels) we are dealing, once again, with strategic and tactical decisions. These can be handled by following a decision making method such as the ones suggested in step 5 of collaborative decision process described in the previous section. In cases that collaborative decision is needed within the company, then the full process can also be followed. On the other hand, when focusing on machine level and device and component level, decision process is required to be more immediate as a quick answer needs to be provided to avoid production stops, errors or faults. Thus, in these cases we are concentrating on operational and real-time decision making.

In the context of manufacturing, operational decision making refers to daily operations within the shop flor. One typical example is related with maintenance decisions. In fact maintenance is a daily operation of industrial plants and, if correctly performed, may contribute positively for their life expectancy. Thus, the minimization of the impact of the maintenance activities in the plant operation, together with the associated costs, is the core of any maintenance strategy [58]. Yet, balancing the two aspects is not always an easy task, especially when time is a constraint. To help solving this issue [59] 
proposes a strategy that combines case-base reasoning with similarity computation and risk assessment. The methodology starts by identifying a set of fundamental aspects related with the plant, namely:

- List of state variables important to assess the maintenance status of the plant;

- List of rules associated to the normal behaviour of those state variables;

- List of common maintenance problems that occur each time a rule is violated;

- List of causes for those problems;

- List of actions to deal with the causes, i.e. maintenance actions to restore normal functioning.

This information must be collected through appropriate sources such as:

- Monitoring systems: information on the current status of the plant.

- Stored operating information: information on normal and abnormal plant operation, especially in terms of failure history.

- Expert Opinions (designers, operators, maintenance staff and engineers): based on interviews to people who work at the plant in a daily basis, together with specific plant information (provided mainly by designers and engineers) that can be used to locate potential problem sources.

- Similar plant information: provide information on similar plants (only useful when similar operating conditions can be guaranteed).

- Engineering analysis: define potential failure operating modes and causes.

Once all this information on the plant is collected it is possible to build a set of Cases that represent what happened in past situations and which decisions were made at that time. By means of similarity computation the cases will be clustered and their characteristics will be used for comparison with new cases. The establishment of correlations between the situations, the actions developed to deal with them and their impact in maintenance operation of the plant will help clarifying the following aspects:

- Identification of what caused the abnormal value;

- Compute the risk of the abnormal situation;

- Assess the result of the maintenance action in the plant;

- Assess the costs of the maintenance action.

The methodology aims at minimizing the costs of a maintenance intervention taking into account the alternatives that presented best performance. Thus, in the end, a compromise is reached and most appropriate maintenance strategy is selected. The process was designed to be validated by human operator at the end. Nonetheless, depending on the level of criticality, it is possible to identify actions that can be automatically implemented by the system instead of requiring human validation at all times. Finally, when it comes to device and component level the kind of decision sought is real-time decision. Devices are typically sensors that are spread along the production process, and also on the products being produced, that are aware of the production steps. In this later case, a product that is in the process of being manufactured carries a digital product memory with it from the very beginning and can communicate with its environment via radio signals. The product thus becomes a CPS that enables the real world and the virtual world to merge [60].

Other cases of device level decision can be found in situations that require self-healing operations [61] or automatic tool selection [62]. In the first case the device must include capabilities to detect a specific fault (e.g. tool wearing). Depending on the degree of complexity, information may come from several devices and combined to detect the fault. Once the fault is detected the system automatically initiates the process of changing the tool with another one in good shape.

\section{Validation}

The validation of the work here proposed has been conducted in multiple stages in the context of different EU projects, each addressing different parts of the concept here presented. Horizontal integration aspects have been tested in the context of IMAGINE ${ }^{7}$ and $\mathrm{C}_{2} \mathrm{NET}^{8}$ projects. The first, tested a novel and comprehensive methodology for the end-to-end management of dynamic manufacturing networks built on demand, following a plug and produce approach. Based on production requirements and constraints, networks with several partnership options are proposed dynamically, hence enabling decision on the most efficient form of managing a collaborative production. The second has the aim of

\footnotetext{
${ }^{7}$ FP7-FoF-ICT-285132 IMAGINE - Innovative End to End Management of Dynamic Manufacturing Networks (http://www.imagine-future-factory.eu)

8 H2020-FoF-636909 C2NET - Cloud Collaborative Manufacturing Networks (http://c2net-project.eu)
} 
creating a set of cloud-enabled tools for supporting the SMEs supply network optimization of manufacturing and logistic assets based on collaborative demand, production and delivery plans. The project is testing the methods for establishing collaboration among partners and is also using optimization to find the best option for a specific collaborative business opportunity, providing the recommendations to the users in order to support decision making. The results achived so far are quite encouraging with a growing number of successful collaboration situations already taking place in four different pilots.

Regarding vertical integration main validation work was performed in the context of InLife ${ }^{9}$ project regarding maintenace, fault diagnostics and selfhealing operations. The results achieved there were also quite promissing especially regarding the possibility to reduce stop times due to unforseen maintenance activities. The companies involved in InLife pilots tested the methods here proposed and all of them registered reduction of production stops and reduction of time to perform maintenance (due to more rapid diagnostics). Also, the work developed in C2NET is validating the concept of manufacturing resources virtualization, "bringing" the phisical devices to cloud where their virtual images can easily be parameterized to enable services such as sensor fusion, filtering, grouping, etc.

Moreover, the complete framewok proposed in the paper is being tested in the context of EU project vfOS ${ }^{10}$. The project captures the notion of a manufacturing "operating system" deployed in a cloud platform, supporting a multi-sided market ecosystem for providing a range of services to the connected factory of the future to integrate better manufacturing and logistics processes. This manufacturing approach can enable a whole new level of flexibility and scalability in the manufacturing domain. vf-OS includes three use cases, all of them with requirements in the area of decision making and two directly related with the manufacturing area (the third one regards construction sector).

Focusing on the manufacturing use cases, the first one involves a Spanish company reference in the development and manufacture of automation

\footnotetext{
${ }^{9}$ FP6-NMP2-CT-2005-517018 InLife - Integrated Ambient Intelligence and Knowledge-Based Services for Optimal LifeCycle Impact of Complex Manufacturing and Assembly Lines (http://cordis.europa.eu/project/rcn/75858_en.html)

${ }^{10}$ H2020-FoF-723710 - vf-OS-Virtual Factory Open Operating System (http://cordis.europa.eu/project/rcn/205550 en.html)
}

production equipment and a Lithuanian company which is an international manufacturer of PhotoVoltaic (PV) glass and provider of solar energy solutions. The second use cases on manufacturing involves two French companies: one specialized in plastic manufacturing and transformation and another expert on engineering and transforming metal parts using several technologies.

Specifically, the main issues identified by the onvolved companie are:

- Decision support for vertical integration:

* Establishment of efficient policies on predictive, preventive and corrective maintenance in terms of spare parts demand forecast and supply chain stakeholders coordination;

* Faster reaction to spare-parts failure due to non-visibility of equipment operation indicators and status;

* Decrease of production downtime and lost profits due to spare-parts failure in industrial high-value capital assets.

- Decision support for horizontal integration:

* Detection of the most appropriate business collaboration opportunities (in B2B schema) among common customer projects.

* Reinforce common commitment system for customer projects in collaborative schema

* Development of reactive tools and mechanisms helping to track and estimate the convergence of manufacturing order operations comparing to customer commitments among the collaborative shopfloors.

Considering the level of decision support required a set of data sources have been selected, namely:

- registries of failures in automation production equipment and other unexpected events

- quality control

- stocking

- maintenace scheduler

- location information of spare-parts and other material

- historical use of spare-parts and associated failures

- hstorical on impact of events

- real-time equipment indicators

- real-time analytics for behaviour prediction

- monitoring information from spare-parts status

- product details

- production process steps and recipies 
- value chain network technical capabilities and availabilities.

The validation scenarios were built taking into consideration the needs from the involved the companies. The scenarios show the total alignment between the decision support strategies here proposed and what companies are really searching for.

\section{Discussion and final considerations}

Regarding the level of complexity of the decision support process, it grows with the number of variables and constraints that needed to be considered. Thus, as previouly explained, a careful selection of these variables is fundamental to ensure process success and explainability (an important aspect of any decision process). Together with the number of variables, and for the specific case of collaborative decisions making, the number of intervenient is also an issue. In fact, the higher the number of intervenient the more complex the process becomes. The definition of a leadership is, for this reason, a critical aspect and must be overlooked. In what concerns operational and/or real time decision making the most important aspect is the profound knowledge about production process. Thus, a careful selection of the information sources and a correct correlation of the information collected are fundamental.

Industry 4.0 represents the fourth industrial revolution and represents a huge opportunity, as well as very demanding challenge, for companies. On the other hand, companies that choose to ignore it may be at stake and will for sure struggle in this new production approach. In this paper the authors start by contextualizing the potential that represents industrial digitalization and how technological advances can contribute for a new perspective on manufacturing production. The barriers here presented to the full implementation of Industry 4.0 vision set the scene to the selection of the areas in which decision support is vital. The areas in which decision support is needed are identified together with the constraints and complexity that are involved in the different processes. The strategies proposed were selected based on two of Industry 4.0 main characteristics: horizontal integration and vertical integration. The other two aspects (i.e. consistent engineering and human-technology synergy) were not considered. This option is somehow the reflex of how companies are looking at the industrial digitalization issues (much more concerns about interoperability issues than with societal aspects).

Validation section demonstrates the impact that the application of the proposed framework may have in industrial scenarios. In fact, the promising results achieved provided important stimulous for the continuation of the work and for its broader testing.

Future perspectives of this work include fine tuning of the methodology to answer new requirements and needs that are being identified in the context of vf-OS project. Future work will also include testing of the proposed strategies in real production environments of Industry 4.0.

\section{Acknowledgements}

The research leading to these results has received funding from the European Union H2020 projects InLife (contract nr. 517018), IMAGINE (contract nr. 285132), C2NET (contract nr. 636909) and vf-OS (contract nr. 723710).

\section{References}

[1] R. C. Schlaepfer, M. Koch and P. Merkofer, Industry 4.0 Challenges and Solutions for the digital transformation and use of exponential technologies, Deloitte AG, 2015.

[2] 7iD, "Industry 4.0". 2016 https://www.7id.com/technology/industry-4-0/

[3] European Commission, “'"Horizon 2020 - Work Program 2016-2017 - Cross-cutting Activities”, 25 July 2016

[4] EFFRA, "Factories of the Future: Multi-annual roadmap for the contractual PPP under the Horizon 2020”, 2013

[5] FInES Research Roadmap Task Force, 2012

[6] B. Hartmann, W. P. King, and S. Narayanan, "Digital manufacturing: The revolution will be virtualized", McKinsey \&Company, August 2015

[7] J. Jacinto, "Smart Manufacturing? Industry 4.0? What's It All About?", Siements Totally Integrated Automation, Automation World \& Design World, July, 2014

[8] L. Monostori, "Cyber-physical Production Systems: Roots, Expectations and R\&D Challenges", Procedia CIRP, Volume 17, Pages 9-13, 2014

[9] P. Adolphs, "RAMI 4.0 - An architectural Model for Industrie 4.0", Platform Industrie 4.0, June 2015

[10] M. Collins, "Why America Has a Shortage of Skilled Workers", Industry Week, April 2015

[11] J. Forbes, N. Naujok, R. Geissbauer, J. Vedso, S. Schrauf, "Industry 4.0: Building the digital enterprise", PWC, 2016

[12] World Economic Forum Industrial Internet Survey, 2014

[13] D. Chen, F. B. Vernadat, "Enterprise Interoperability: A Standardisation View" Enterprise Inter- and IntraOrganizational Integration, Volume 108 of the series IFIP - The International Federation for Information Processing pp 273-282, 2003 
[14] Yan, L., Li, Z., \& Yuan, X. (2009). study on Method-ofrobust-multidisciplinary-design-collaborative-decision for product design,. Information Technology Journal, 8(4), 441-452.

[15] Ruiz Dominguez, G. A. (2005). Caractérisation de l'activité de conception collaborative à distance : étude des effets de synchronisation cognitive.

[16] Jung, J. J. Reusing ontology mappings for query routing in semantic peer-to-peer environment, Information Sciences, 2010. - doi:10.1016/j.ins.2010.04.018

[17] Ranjan, R., Zhao, L., Wu, X., Liu, A., Quiroz, A., Parashar, M. Peer-to-Peer Cloud Provisioning: Service Discovery and Load-Balancing - doi: 10.1007/978-1-84996-241-4_12

[18] Agostinho, C., Pinto, P., \& Jardim-goncalves, R. Dynamic Adaptors to Support Model-Driven Interoperability and Enhance Sensing Enterprise Networks. In 19th World Congress of the International Federation of Automatic Control (IFAC'14). Cape Town, South Africa, 2014.

[19] Chen, D., Doumeingts, G., Vernadat, F. Architectures for enterprise integration and interoperability: Past, present and future, Comput. Ind. 59 647-659, 2008 doi:10.1016/j.compind.2007.12.016

[20] Ducq, Y., Chen, D., Alix, T. Principles of Servitization and Definition of an Architecture for Model Driven Service System Engineering, in: 4th Int. IFIP Work. Conf Einterprise Interoperability (IWEI 2012), Harbin, China, 2012. doi:10.1007/978-3-642-33068-17 12

[21] Elvesæter, B., Hahn, A., Berre, A., Neple, T. Towards an interoperability framework for model-driven development of software systems, in: 1st Int. Conf. Interoperability Enterp. Softw. Appl., Springer, 2005. http://www.springerlink.com/index/L10NU4306N054T6G.p df.

[22] $\overline{O M G}$, MDA Guide Version 1.0.1 (omg/2003-06-01), Object Management Group, 2003. http://www.omg.org/cgibin/ doc?omg/03-06-01.pdf

[23] Agostinho, C., Ducq, Y., Zacharewicz, G., Sarraipa, J. Lampathaki, F., Poler, R., \& Jardim-Goncalves, R. Towards acsustainable interoperability in networked enterprise information systems: Trends of knowledge and modeldriven technology. Computers in Industry. 2015 , doi:10.1016/j.compind.2015.07.001

[24] Santucci, G., Martinez, C., Vlad-câlcic, D. The Sensing Enterprise, in: FInES Work. FIA 2012, Aalborg, Denmark, 2012

[25] Sriram, R. Smart Networked Systems and Societies: What Will the Future Look Like?, in: IEEE IT Prof. Conf. (IT Pro), IEEE Computer Society, 2014

[26] J. Manyika, M. Chui, B. Brown, J. Bughin, R. Dobbs, C. Roxburgh, et al., Big data: The next frontier for innovation, competition, and productivity, 2011. http://www.mckinsey.com/insights/business technology/big _da ta_the_next_frontier_for_innovation

[27] G. Zacharewicz, S. Diallo, Y. Ducq, C. Agostinho, R Jardim-Goncalves, H. Bazoun, Z. Wang, G. Doumeingts, "Model-based approaches for interoperability of nex generation enterprise information systems: state of the art and future challenges", Inf. Syst. E-Bus Manage, 2016. doi:10.1007/s10257-016-0317-8

[28] Jardim-Goncalves, R., Agostinho, C. \& Steiger-Garcao, A A reference model for sustainable interoperability in networked enterprises: towards the foundation of EI science base, International Journal of Computer Integrated Manufacturing, Special Issue on Collaborative Manufacturing and Supply Chains, Volume 25, Issue 10 2012 - doi:10.1080/0951192X.2011.653831
[29] Schneeweiss, C., (2003). "Distributed Decision Making in Supply Chain Management." Int. J. of Production Economics 84: 71-83.

[30] Alemany, M.M.E., F. Alarcón, F.C. Lario, J.J. Boj., (2011) An Application to Support the Temporal and Spatial Distributed Decision- Making Process in Supply Chain Collaborative Planning. Computers in Industry 62 (5): 519 40. doi:10.1016/j.compind.2011.02.002.

[31] Hong, I.H., J.C. Ammons, M.J. Realff., (2008). Centralized versus Decentralized Decision-Making for Recycled Material Flows. Environmental Science \& Technology 42 (4): 1172-77.

[32] Pibernik, Richard, Eric Sucky. (2007). An Approach to Inter-Domain Master Planning in Supply Chains. Int. J. of Production Economics 108: 200-212. doi:10.1016/j.ijpe.2006.12.010.

[33] Lee, H., S. Whang., (1999). "Decentralized Multi-Echelon Supply Chains: Incentives and Information." Management Science 45 (5): 633-640.

[34] Jung, H., F. Chen, and B. Jeong., (2008). Decentralized Supply Chain Planning Framework for Third Party Logistics Partnership. Computers \& Industrial Engineering 55 (2): 348-64. doi:10.1016/j.cie.2007.12.017.

[35] Wang, K.-J., and M.-J. Chen., (2009). Cooperative Capacity Planning and Resource Allocation by Mutual Outsourcing using Ant Algorithm in a Decentralized Supply Chain. Expert Systems with Applications 36 (2):2831-2842.

[36] Simon, H. A. (1969). The Science of the Artificial. MIT Press, Cambridge, Mass, 1st ed. [3rd ed. in 1996, MIT Press]

[37] Mesarovic, M. D., Masko, D. and Takahara, Y. (1970), Theory of Hierarchical Multilevel Systems, New York and London, Academic Press

[38] D. Schatsky, C. Muraskin, "Blockchain is coming to disrupt your industry", Deloitte, December 2015

[39] L.M. Camarinha-Matos, H.J. Afsarmanesh, "Collaborative networks: a new scientific discipline", Journal of Intelligent Manufacturing, Volume 16, Issue 4, pp 439-452, 2005

[40] Popplewell, K., Stojanovic, N., Abecker, A., Apostolou, D., Mentzas, G., \& Harding, J. (2008). Supporting adaptive enterprise collaboration through semantic knowledge services. Enterprise Interoperability Iii: New Challenges and Industrial Approaches, (c), 381-393. http://doi.org/10.1007/978-1-84800-221-0 30

[41] Agostinho, C., Ducq, Y., Zacharewicz, G., Sarraipa, J, Lampathaki, F., Jardim-Goncalves, R., \& Poler, R. (2015). Towards a Sustainable Interoperability in Networked Enterprise Information Systems: Trends of Knowledge and Model-Driven Technology. Accepted for Publication at Computers in Industry. http://doi.org/10.1016/j.compind.2015.07.001

[42] Agostinho, C., \& Jardim-Gonçalves, R. (2015). Sustaining interoperability of networked liquid-sensing enterprises: A complex systems perspective. Annual Reviews in Control, 39, 128-143. http://doi.org/10.1016/j.arcontrol.2015.03.012

[43] Weichhart, G., Molina, A., Chen, D., Whitman, L. E., \& Vernadat, F. (2015). Challenges and current developments for Sensing, Smart and Sustainable Enterprise Systems. Computers in Industry. http://doi.org/10.1016/j.compind.2015.07.002

[44] Weichhart, G. (2013). Supporting Interoperability for Chaotic and Complex Adaptive Enterprise Systems. On the Move to Meaningful Internet Systems: OTM 2013 Workshops. Confederated International Workshops: OTM Academy, OTM Industry Case Studies Program, ACM, EI2N, ISDE, META4eS, ORM, SeDeS, SINCOM, SMS, 
and SOMOCO 2013. Proceedings: LNCS 8186, 86-92. http://doi.org/10.1007/978-3-642-41033-8 14

[45] D. P. Truex, R. Baskerville, H. Klein, "Growing systems in emergent organizations", Magazine Communications of the ACM CACM Homepage archive, Volume 42 Issue 8, Pages 117-123, Aug. 1999

[46] S. Weiberg, "Facilitating Collaborative Decision-Making in Six Steps", International Association of Facilitators Annual Meeting, pp 14-15, 1999

[47] A. L. Delbecq, A. H. VandeVen, "A Group Process Model for Problem Identification and Program Planning". Journal Of Applied Behavioral Science. 7: 466-492, 1971. doi: $10.1177 / 002188637100700404$.

[48] T. L. Saaty, "The Analytic Hierarchy Process", N. York, USA: McGraw-Hill, 1980.

[49] Lucke, D., Constantinescu, C., Westkämper, E. (2008) Smart factory-a step towards the next generation of manufacturing. Manufacturing Systems and Technologies for the New Frontier (pp. 115-118). Springer London.

[50] Weiser, M. (1991). The Computer for the 21st Century. Scientific American, Special Issue on Communications, Computers, and Networks. Sep. 1991

[51] Westkämper, E.; Jendoubi, L.; Eissele, M.; Ertl, T. (2006). Smart Factory Bridging the gap between digital planning and reality. Manufacturing Systems 35, No. 4, p. 307-314.

[52] Goryachev, A., Kozhevnikov, S., Kolbova, E., Kuznetsov, O., Simonova, E., Skobelev, P., Tsarev, A., Shepilov, Y., (2012). "Smart Factory": Intelligent System for Workshop Resource Allocation, Scheduling, Optimization and Controlling in Real Time. Advanced Materials Research, Vol. 630, pp. 508-513, Dec. 2012.

[53] Agostinho, C.; Marques-Lucena, C.; Sesana, M.; Felic, A.; Fischer, K.; Rubattino, C.; Sarraipa; J. (2015). OSmosis Process development for innovative product design and validation. 2015 ASME IMECE, Houston, USA

[54] Ko, J.; Lee, B.; Lee, K.; Hong, S.G.; Kim, N.; Paek, J. (2015). Sensor Virtualization Module: Virtualizing IoT
Devices on Mobile Smartphones for Effective Sensor Data Management. Int. J. of Distributed Sensor Networks, 2015. doi:10.1155/2015/730762

[55] Guo, T.; Papaioannou, T. G.; Aberer, K. (2014). Efficient Indexing and Query Processing of Model-View Sensor Data in the Cloud. J. of Big Data Research, vol. 1, p. 52-65.

[56] Kumra, S.; Sharma, L.; Khanna, Y.; Chattri, A. (2012). Analysing an Industrial Automation Pyramid and Providing Service Oriented Architecture. Int. J. of Engineering Trends and Technology, 3(5), pp. 586-594

[57] Santucci, G., Martinez, C., \& Vlad-câlcic, D. (2012). The Sensing Enterprise. FInES Workshop at FIA. Aalborg, Denmark

http://www.theinternetofthings.eu/sites/default/files/\%5Bus ername $\% 5 \mathrm{D} /$ Sensing-enterprise.pdf

[58] VTT, "Operational decision making in the process industry", Teemu Matasniemi (Ed.), Tampere, 2008

[59] Marques, M., Neves-Silva, R. Risk Based Decision Support System for Life Cycle Management of Industrial Plants. 9th IEEE International Conference on Industrial Informatics, Lisbon

[60] K. Nikolaus, "Building the nuts and bolts of self-organizing factories", Manufacturing and Innovation - Industry 4.0, Siemens, Pictures of the Future, Spring 2013

[61] Ribeiro, L., Barata, J., and Colombo, A. W., "MAS and SOA: A Case Study Exploring Principles and Technologies to Support Self-Properties in Assembly Systems." International Workshop on Self-Adaptation for Robustness and Cooperation in Holonic Multi-Agent Systems, IEEE, Venice, 2008.

[62] Ubisense, "Smart Factory - Automotive Assembly", CAS Assembling Tooling and Services, 2014 http://cas-ltd.uk.com/wpcontent/uploads/2016/03/EN SF ASS SDEVICE FS V1.p df 